\title{
KONSTRUKSI KOMPETENSI PEDAGOGIK GURU DALAM PEMBELAJARAN
}

\author{
Rahmat Solihin', Muhammad Iqbal'2, Muhammad Tamsil Muin ${ }^{3}$ \\ 123Sekolah Tinggi Agama Islam Asy-Syukriyyah Tangerang; Indonesia \\ E-mail: solihin.elrahmat@gmail.com
}

\begin{abstract}
Pedagogical Content Knowledge is a concept in education research initiated by Shulman in 1986. The PCK concept seeks to uncover the teacher competence construct to produce quality learning. This study aims to describe the concept of PCK, which is a competency construct that teachers must possess in education. Using library research, the authors search for a relevant reference regarding PCK as primary data in this study. The author concludes that PCK combines teacher knowledge about pedagogy and teacher knowledge about content or learning subjects. These two competencies are interrelated and reinforce each other so that neither can be left out. A teacher must understand what he teaches before he teaches the knowledge to his students. This is what distinguishes a teacher from a scientist who focuses on developing knowledge, while the teacher focuses more on transforming the delivery of knowledge to students.
\end{abstract}

Keywords; PCK; Pedagogical Content Knowledge; Teacher Competence.

\section{PENDAHULUAN}

Problematika pendidikan yang terjadi menuntut para akademisi untuk mencari solusi agar kualitas pendidikan menjadi lebih baik. Salah satu konsep dalam pendidikan yang memiliki potensi dalam meningkatkan kualitas pendidikan di Indonesia adalah konsep Pedagogical Content Knowledge (PCK). Konsep PCK merupakan sebuah konsep yang mengkombinasikan dua unsur penting dalam pembelajaran, yaitu Content Knowledge (CK) dan Pedagogical Knowledge (PK) (Shulman, 1986, 1987).

Konsep PCK mulai mendapatkan perhatian yang lebih pada ranah akademisi dan praktisi setelah sebelumnya, paradigma pendidikan lebih menekankan pada SMK (Subject Matter Knowledge), yaitu pengetahuan mengenai subjek materi yang diajarkan. PCK menjadi sebuah jawaban, di mana guru tidak hanya harus menguasai subjek atau konten pembelajaran saja, akan tetapi juga menguasai bagaimana cara mengajarkan konten tersebut dalam sebuah pembelajaran. Dalam PCK, guru diharuskan untuk dapat mentransformasikan suatu materi atau konten ke dalam bentuk pembelajaran di kelas yang dapat memberikan pemahaman kepada siswa (MKDP, 2011; Sulastri, 2016). Para ahli dan praktisi menyadari bahwa, pengetahuan tentang materi mata pelajaran maupun pengetahuan pedagogik, keduanya merupakan hal yang krusial dalam pembelajaran serta sangat berpengaruh dalam meningkatkan pemahaman siswa (Shulman, 1987). Penelitian lain yang sebelumnya telah dilakukan untuk mengungkap PCK ini dapat dilihat pada Tabel 1 berikut. 
Tabel 1. Penelitian Terdahulu.

\begin{tabular}{|c|c|c|}
\hline No. & Judul Penelitian & Distingsi \\
\hline 1 & $\begin{array}{l}\text { Membangun Pedagogical Content Knowledge } \\
\text { Calon Guru Fisika Melalui Praktek Pengalaman } \\
\text { Lapangan Berbasis Lesson Study. Lia Yuliati. } \\
2017\end{array}$ & $\begin{array}{l}\text { Penelitian Yuliati mengedepankan } \\
\text { fokusnya pada persiapan calon guru } \\
\text { fisika dengan membangun PCK yang } \\
\text { baik. Penelitian ini menganalisis PCK } \\
\text { pada kegiatan PPL yang dilakukan. }\end{array}$ \\
\hline 2 & $\begin{array}{l}\text { Pedagogical Content Knowledge (PCK) Calon } \\
\text { Guru SD Melalui Mata Kuliah Pengembangan } \\
\text { dan Praktik Pembelajaran Bahasa Dan Sastra } \\
\text { SD. M. Fakhrur Saifudin dan Hanum Hanifa } \\
\text { Sukma. } 2018\end{array}$ & $\begin{array}{l}\text { Saifudin dan Sukma berfokus pada } \\
\text { pengembangan PCK kepada calon } \\
\text { guru bahasa dan sastra. } \\
\text { Mengintegrasikan muatan yang pada } \\
\text { PCK dalam proyek yang dilakukan } \\
\text { oleh mahasiswa. }\end{array}$ \\
\hline 3 & $\begin{array}{l}\text { Technological Pedagogical and Content } \\
\text { Knowledge (TPACK): The Students' Perspective } \\
\text { on Writing Class. Farikah dan Moch. Malik Al } \\
\text { Firdaus. } 2020\end{array}$ & $\begin{array}{l}\text { Farikhah dan Firdaus meneliti TPACK } \\
\text { sebagai pengembangan dari PCK pada } \\
\text { mahasiswa terhadap dosen. } \\
\text { Penelitian ini menunjukkan } \\
\text { kemampuan dosen yang memiliki } \\
\text { TPACK akan berpengaruh terhadap } \\
\text { kualitas perkuliahan. }\end{array}$ \\
\hline
\end{tabular}

Content Knowledge yang baik adalah penguasaan dan pemahaman materi yang mendalam terhadap subjek (mata pelajaran) secara menyeluruh. Hal tersebut harus seimbang dengan Pedagogical Knowledge atau cara mengajar dan mengelola kelas, agar tercipta pembelajaran yang efektif. Akan tetapi, berdasarkan penelitian, kebanyakan guru mengalami kesulitan dalam mengintegrasikan Content Knowledge dengan Pedagogical Knowledge ini dalam pembelajaran (Purwaningsih, 2015). Beberapa studi menunjukan bahwa guru kurang memahami bagaimana mengajarkan suatu pemahaman konseptual dan konten yang akan diajarkan, padahal guru tersebut sudah memahami konten tersebut dengan baik. Hal ini disebabkan karena banyaknya guru yang lebih menekankan pemahamannya terhadap Content Knowledge dibandingkan dengan Pedagogical Knowledge (Gultom \& Mampouw, 2019; Subhan, 2020).

Berdasarkan penjabaran ini, maka dapat diketahui bahwa konsep PCK merupakan konsep yang sangat penting untuk dipelajari, terlebih bagi calon pendidik dan para praktisi yang sudah bergelut dalam lembaga pendidikan. Dengan memahami konsep PCK dalam konstruknya pada pembelajaran, maka diharapkan akan tercipta tenaga pendidik yang berkualitas dan akan tercipta pula pembelajaran yang efektif pada setiap pembelajaran di kelas. Melalui penelitian ini 
diharapkan pembaca dapat memahami lebih dalam mengenai konsep PCK. Oleh karena itu, tujuan dari penelitian ini adalah untuk mendeskripsikan konsep PCK yang merupakan konstruk kompetensi yang harus dimiliki guru dalam pembelajaran.

\section{METODE}

Pendekatan dalam penelitan ini adalah pendekatan kualitatif yang bersifat deskriptifinterpretatif. Jenis penelitian yang digunakan adalah library research. Sedangkan data yang diperoleh adalah narasi deskriptif mengenai Pedagogical Content Knowledge (PCK) dalam pembahasannya tentang konstruk kompetensi guru dalam pembelajaran. Sebagai penelitian library research, teknik pengumpulan data yang digunakan dalam penelitian ini adalah dengan menggunakan teknik dokumentasi, dengan mengumpulkan data yang berasal dari berbagai literatur yang relevan, terutama tentang konsep PCK yang menjadi literatur pokok dalam pembahasan, untuk kemudian data ini diinterpretasikan menjadi narasi kritis terhadap judul yang dibahas dalam penelitian.

\section{HASIL DAN PEMBAHASAN}

\section{Konsep Pedagogical Content Knowledge (PCK)}

Berbicara mengenai konsep PCK, maka akan lebih baik untuk membahas bagaimana konsep PCK dikemukakan oleh pencetusnya, yaitu Shulman pada tahun 1986. PCK muncul berdasarkan penelitian-penelitian yang telah dilakukan para ahli terkait dengan pendidikan. Meskipun pada awalnya PCK lebih berkenaan dengan pendidikan pada bidang sains, PCK memberikan dampak yang signifikan terhadap pendidikan pada bidang-bidang lain sehingga konsep mengenai PCK ini semakin berkembang luas.

Sejak lama, para peneliti telah mempelajari faktor-faktor yang mempengaruhi efektivitas interaksi dalam pembelajaran. Penelitian-penelitian tersebut memiliki beberapa kesamaan dalam pendekatan yang mereka gunakan untuk mempelajari kinerja guru di dalam pembelajaran. Dua pendekatan ini yaitu pendekatan yang memandang interaksi pembelajaran dari perspektif perilaku guru dalam kelas dan kemudian pendekatan yang lebih lebih memandang dari perspektif kognitif guru.

1. Pendekatan pertama yaitu pendekatan yang melihat interaksi pembelajaran dari perspektif perilaku guru dalam kelas. Pendekatan ini lebih berfokus kepada hal-hal yang dilakukan oleh guru saat mengajar, atau metode yang digunakan guru dalam mengelola kelas saat pembelajaran berlangsung. Pandangan pada pendekatan ini meyakini bahwa aktivitas guru di dalam kelas sangat besar pengaruhnya terhadap keberhasilan belajar siswa (Wentzel \& Brophy, 2014). Pendekatan ini sering digunakan dalam penelitian-penelitian korelasional yang mencari hubungan antara penerapan metode tertentu dengan efektivitas ketercapaian 
pembelajaran, misalnya pengaruh penerapan metode $\mathrm{x}$ terhadap prestasi belajar siswa atau korelasi penggunaan strategi pembelajaran x dengan nilai akhir siswa (Solihin et al., 2021). Metode pembelajaran yang digunakan oleh guru berpengaruh langsung terhadap hasil belajar siswa sehingga dalam penelitian pendidikan, pendekatan ini dikenal sebagai pendekatan proses-produk.

2. Pendekatan kedua lebih memandang perspektif kognitif guru. Pendekatan ini berdasar dari asumsi psikologi kognitif yang beranggapan bahwa aktivitas guru adalah manifestasi atau realisasi dari pandangan dan pengetahuan guru secara kontekstual. Pendekatan ini meyakini bahwa struktur pengetahuan dan mental seorang guru memainkan peran utama di dalam cara seseorang memandang, memahami, berpikir, dan melakukan tindakan sehingga berpengaruh terhadap kemampuan dia dalam mengajar (Putnam \& Borko, 2000). Menurut pandangan ini, guru memiliki suatu pengetahuan khas yang menjadi dasar aktivitasnya di dalam pembelajaran. Pandangan ini menjadi dasar berkembangnya bidang penelitian yang dikenal sebagai knowledge base for teaching (KBT).

Dua pendekatan ini saling melengkapi dan hingga sekarang masih terus berkembang dengan luas. Pendekatan pertama lebih banyak menggunakan metode observasi dan penggunaan serta analisis data secara kuantitatif, sementara pendekatan kedua lebih banyak menggunakan data serta analisis kualitatif. Pendekatan pertama fokus pada kegiatan guru dan capaian belajar siswa, sementara pendekatan kedua lebih berfokus pada aktivitas guru untuk masuk mendalami alasan guru bertindak atau pemikiran yang menjadi latar belakang dari tindakan tersebut. Hingga saat ini, pendekatan kedua lebih berkembang dibandingkan dengan pendekatan pertama karena kemungkinan pembahasannya sangat luas.

Konsep Pedagogical Content Knowledge (PCK) berkembang berdasarkan model penelitian Knowledge base for teaching (KBT). Istilah PCK pertama kali dikemukakan oleh Shulman pada tahun 1986 dalam tulisannya yang berjudul "Those Who Understand: Knowledge Growth for Teaching" yang dimuat dalam jurnal ilmiah Educational Researcher (Shulman, 1986). Di dalam tulisan tersebut, Shulman pertama kali menguraikan tentang pedagogical content knowledge yang merupakan paradigma baru dari perspektif teacher knowledge.

PCK terdiri dari pengetahuan pedagogi dan pengetahuan materi atau dapat dipahami dengan bahasa sederhana sebagai pengetahuan tentang materi dan cara mengajarkannya. PCK dapat diartikan pula sebagai kemampuan seseorang dalam mentransfer pengetahuannya kepada orang lain. Lebih rinci lagi, Shulman menyatakan bahwa PCK yaitu: Cara-cara yang dapat mewakili atau merumuskan materi sehingga membuat orang lain paham; Pemahaman tentang sebab suatu materi pembelajaran tertentu apakah termasuk dalam kategori sulit atau mudah (tingkat kesulitan materi); Pemahaman bahwa siswa dengan berbagai usia dan latar belakang dapat berpengaruh terhadap apa yang diajarkan pada topik pembelajaran tertentu (Turnuklu \& 
Yesildere, 2007). Pernyataan tersebut berarti PCK merupakan cara merepresentasikan dan merumuskan suatu materi atau subyek pembelajaran, sehingga materi itu dapat dipahami secara menyeluruh oleh siswa.

Dengan bahasa yang berbeda, PCK dapat didefinisikan juga sebagai pengetahuan yang merupakan perpaduan antara pengetahuan konten dan pedagogik, pengetahuan tentang caracara merepresentasikan dan menjelaskan suatu materi untuk membuat materi tersebut dapat dipahami oleh orang lain (Ma'rufi \& Ilyas, 2010). PCK berhubungan dengan cara guru menghubungkan pengetahuan materi yang diajarkan dengan pengetahuan tentang cara mengajar dan alasan tentang memadukan pengetahuan materi menjadi bagian dari proses pembelajaran (Harris et al., 2009). Guru harus paham terlebih dahulu suatu materi, baru kemudian paham bagaimana cara mengajarkan materi tersebut.

Menurut John Dewey, seorang akademisi ataupun ilmuwan menggunakan pengetahuannya untuk mengidentifikasi suatu persoalan, dan kemudian mengembangkan ilmu tersebut. Sementara itu, seorang guru tidak berpikir tentang pengembangan ilmu, ia lebih berpikir tentang mentransformasikan pengetahuannya menjadi pengalaman belajar muridnya.

Shulman beranggapan bahwa guru memiliki suatu bentuk atau struktur pengetahuan yang berbeda dengan ilmuwan. Ketika seorang guru menguasai suatu cabang ilmu atau suatu konsep tertentu ia kemudian berpikir tentang bagaimana pengetahuannya itu dapat diajarkan dengan baik kepada siswanya sehingga pengetahuan guru menjadi bagian dari pengetahuan siswa. Guru mengembangkan cara-cara atau pengalaman belajar yang harus dilakukan oleh siswa agar menguasai pengetahuan itu.

Dengan demikian, dapat disimpulkan bahwa PCK merupakan pengetahuan unik yang membedakan antara ilmuwan dengan guru, antara ahli matematika dengan guru matematika, antara sastrawan dengan guru sastra, dan lain sebagainya. Inilah yang membuat konsep mengenai PCK ini sangat penting untuk dipelajari dan dikembangkan, demi terciptanya pembelajaran yang efektif dan mendapatkan hasil pembelajaran terbaik.

\section{Komponen-Komponen PCK}

Shulman sebagai ahli yang pertama kali melakukan kajian tentang Pedagogical Content Knowledge ini memberikan gagasan bahwa PCK merupakan bentuk representasi paling bermanfaat dari ide, ilustrasi, analogi, penjelasan, dan demonstrasi di dalam suatu pembelajaran. Dengan kata lain, PCK merupakan cara merepresentasi dan memformulasi pelajaran sehingga menjadi mudah untuk dipahami orang lain.

Shulman menggarisbawahi bahwa PCK terdiri atas beberapa hal yaitu: (1) pengetahuan tentang cara-cara menjelaskan dan mempresentasikan suatu materi untuk membuat materi itu dapat dipahami dengan baik; (2) pengetahuan tentang prakonsepsi, dan konsepsi siswa yang 
berbeda usia serta latar belakang yang mereka bawa saat belajar; dan (3) PCK juga berkenaan terhadap suatu pemahaman tentang apa yang membuat suatu pelajaran tentang topik tertentu mudah ataupun sulit. Meskipun pada awalnya konsep mengenai PCK lebih berfokus pada pendidikan sains, akan tetapi PCK lebih berkembang pada semua bidang pendidikan karena begitu kuatnya pengaruh PCK terhadap kualitas pembelajaran.

\section{Gambar 1. Pedagogical Content Knowledge}

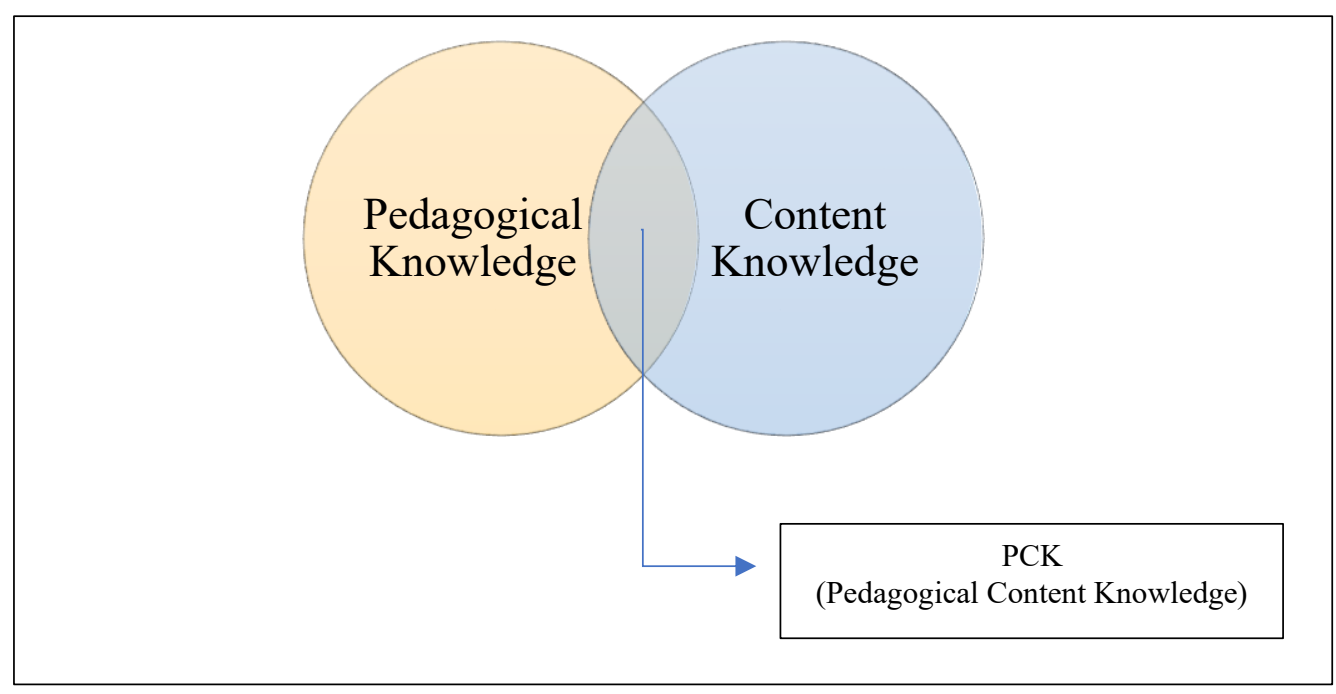

Dari Gambar 1 di atas dapat dipahami bahwa PCK merupakan kombinasi antara dua kompetensi yang dimiliki oleh guru yaitu pedagogical knowledge dan content knowledge. Keduanya harus dikembangkan oleh guru sehingga menghasilkan pemahaman dan cara mengajar yang baik kepada siswa. Dengan bahasa sederhana, seorang guru tidak akan bisa mengajar dengan baik tanpa pengetahuan tentang materi pembelajaran, meskipun kemampuan mengajarnya sudah terbentuk lama melalui pengalaman. Begitu pula sebaliknya, seorang guru yang begitu menguasai tentang suatu materi pembelajaran akan tetapi kemampuan mengajarnya belum terbentuk, akan tetap kesulitan dalam mengajarkan materi tersebut.

Pembahasan mengenai komponen-komponen PCK akan bisa terus berkembang karena penelitian tentang hal ini masih terus dilakukan oleh para praktisi dan akademisi. Dengan berkembangnya metode penelitian untuk mengungkap PCK maka diharapkan konsep mengenai PCK semakin dipahami dan digunakan dalam pendidikan. Untuk itu, perlu adanya penelitian lebih lanjut mengenai pembahasan tentang komponen-komponen PCK ini.

\section{Implementasi Teori PCK dalam Pembelajaran}

Banyak penelitian yang dilakukan mengenai implementasi dari teori PCK dalam pendidikan sehingga PCK tidak hanya menjadi bahan teori saja, melainkan benar-benar mampu menjadi landasan dan pegangan guru serta para peneliti dalam mengetahui bagaimana efektifitas 
Scaffolding: Jurnal Pendidikan Islam dan Multikulturalisme Vo. 3, No. 2, Juli-Desember 2021: 85-94

pembelajaran dengan berbasis teori PCK ini. Di antara beberapa penelitian tersebut menyatakan bahwa teori PCK yang digagas oleh para ahli ini sangat besar pengaruhnya untuk mengetahui kemampuan guru dalam mengajar di kelas. Untuk lebih jelas mengenai beberapa hasil penelitian tersebut dapat dilihat pada Tabel 2 berikut.

\section{Tabel 2. Studi tentang PCK}

Peneliti Hasil Penelitian

Christine Iriane Gultom, PCK merupakan hal penting yang harus dikuasai oleh guru dan calon guru, dkk. karena berkaitan dengan bagaimana seorang guru mengajarkan konten tertentu untuk meningkatkan pemahaman siswa. (Gultom \& Mampouw, 2019)

Bilge Can, dkk. PCK menjadi salah satu tolak ukur dalam mengukur kemampuan guru bahkan juga calon guru dalam mengajar di kelas. (Can et al., 2017)

\section{T. Hartati} Teori PCK dapat digunakan dalam menganalisis kesulitan yang dialami guru ketika implementasi K-13. Di antara kesulitan tersebut antara lain: Materi ajar dianggap sulit untuk dirinci karena KD terlalu luas; guru kesulitan dalam memadukan KD (Kompetensi Dasar); dan guru belum terbiasa melaksanakan PBL, pendekatan saintifik, dan PAKEM secara baik, karena kompetensi pedagogik guru masih terbatas. (Hartati, 2016)

Riawan Y. Purwoko Kemampuan guru dalam memahami materi dan mengelola pembelajaran sangat menentukan peningkatan kualitas pembelajaran di kelas. PCK menjadi sangat penting untuk dimiliki oleh seorang guru dalam mengelola pembelajaran tersebut sehingga guru mampu menciptakan pembelajaran yang bermakna bagi siswa. (Purwoko, 2017) guru, sehingga teori PCK diimplementasikan dalam program PPL yang dilaksanakan oleh kampus. PPL berbasis lesson study digunakan sebagai salah satu alternatif model pembekalan PPL yang mengacu pada konsep PCK. Hal ini didukung oleh banyak hasil penelitian yang menunjukkan bahwa kemampuan PCK para calon guru dapat dipengaruhi oleh pengalaman melaksanakan pembelajaran dan proses praktik serta pelatihan selama pendidikan di perguruan tinggi. (Yuliati, 2017) 
Berdasarkan Tabel 2, secara singkat dapat dikatakan bahwa konsep PCK yang pertama kali digagas oleh Shulman pada tahun 1986 ini telah berkembang tidak hanya sebagai bahan kajian dalam penelitian saja, akan tetapi sudah menjadi konsep dalam pendidikan yang begitu besar pengaruhnya terhadap kualitas pendidikan. Bahkan pada beberapa negara juga telah mengadopsi teori PCK ini ke dalam dokumen kebijakan pemerintah mengenai pendidikan, khususnya pendidikan guru dan pengembangan profesionalisme guru (Sarkim, 2015). Untuk itu, di negara kita juga perlu untuk mengadopsi teori ini dalam rangka untuk meningkatkan efektifitas pembelajaran sehingga berpengaruh pada kualitas pendidikan.

Konsep PCK sejatinya sebagian besar sudah tertuang dalam Undang-Undang tentang pendidikan di Indonesia meskipun tidak secara tertulis mengatakan bahwa ini merupakan konsep dari PCK itu sendiri. Menurut UU Nomor 14 Tahun 2005 Tentang Guru dan Dosen, salah satu kompetensi yang wajib dikuasai oleh guru adalah kompetensi pedagogik. Kompetensi pedagogik merupakan syarat utama dalam menyelenggarakan pembelajaran yang efektif bagi para siswa untuk mencapai tujuan pendidikan. Hal ini senada dengan konsep PCK di mana kompetensi pedagogik merupakan aspek penting dalam pembelajaran.

Berikutnya, content knowledge yang meliputi pengetahuan konsep, teori, kerangka berpikir, ide, metode pembuktian dan bukti (Shulman, 1986) yang menjadi pengetahuan utuh bagi guru tentang subjek materi pelajaran tertentu, juga harus dikuasai oleh guru. Hal senada dengan content knowledge ini adalah mengenai kompetensi profesional yang tercantum dalam PP No. 74 tahun 2008 Pasal 3 yaitu kompetensi profesional adalah kemampuan guru dalam menguasai pengetahuan bidang ilmu pengetahuan, teknologi, seni dan budaya yang diampunya. Pentingnya pemahaman mengenai Content Knowledge dan Pedagogical Knowledge pada guru, diatur sedemikian rupa untuk memudahkan guru maupun calon guru membelajarkan siswa secara optimal.

Uraian tentang PCK yang sudah dijabarkan ini memberikan pemahaman kepada kita bahwa konsep PCK merupakan teori yang sangat penting dan sangat perlu untuk diimplementasikan pada pendidikan di Indonesia. Seorang guru harus paham terhadap apa yang diaajarkan sebelum dia mengajarkan itu kepada siswanya. Di dalam konstruk kompetensi seorang guru terdapat suatu kompetensi yang merupakan ciri khas dari profesi seorang guru itu sendiri. PCK dibangun berdasarkan pengetahuan tentang konten/materi pembelajaran yang dipadukan dengan pengetahuan pedagogis.

\section{KESIMPULAN}

Pedagogical content knowledge atau PCK merupakan sebuah terobosan dalam dunia pendidikan mengenai kompetensi apa yang harus dikuasai oleh guru dalam meningkatkan kualitas mengajar mereka. Konsep PCK adalah kombinasi antara pengetahuan pedagogik guru dengan pengetahuan 
konten dari subjek pembelajaran. Seorang guru harus paham terhadap apa yang diajarkan sebelum dia mengajarkan itu kepada siswanya. Kedua kompetensi ini saling berkaitan dan menguatkan satu sama lain sehingga tidak bisa ditinggalkan salah satu maupun keduanya. Dengan pembahasan mengenai PCK ini peneliti berharap para akademisi dan praktisi pendidikan bisa lebih banyak mengambil referensi dari konsep PCK dalam rangka meningkatkan kualitas pendidikan.

\section{BIBLIOGRAFI}

Can, B., Erokten, S., \& Bahtiyar, A. (2017). An Investigation of Pre-Service Science Teachers' Technological Pedagogical Content Knowledge. European Journal of Educational Research, 6(1), 51-57. https://doi.org/10.12973/eu-jer.6.1.51

Gultom, C. I., \& Mampouw, H. L. (2019). Analisis Pedagogical Content Knowledge Guru dan Calon Guru pada Pembelajaran Matematika. Jurnal Cendekia : Jurnal Pendidikan Matematika, 3(1), 149-163. https://doi.org/10.31004/cendekia.v3i1.91

Harris, J., Mishra, P., \& Koehler, M. (2009). Teachers' technological pedagogical content knowledge and learning activity types: Curriculum-based technology integration refrained. Journal of Research on Technology in Education, 41(4), 393-416. https://doi.org/10.1080/15391523.2009.10782536

Hartati, T. (2016). PCK (pedagogical content knowledge) bagi mahasiswa S-2 pendidikan dasar dalam rangka implementasi kurikulum 2013. Jurnal Pendidikan Sains Sosial Dan Kemanusiaan, 9(1), 2-6.

Ma'rufi, \& Ilyas, M. (2010). Tinjauan Teoritis Tentang Pengembangan Pedagogical Content Knowledge Guru Melalui Lesson Study. Pedagogy, 2(1), 106-160.

MKDP, T. (2011). Kurikulum dan Pembelajaran. Rajawali Press.

Purwaningsih, E. (2015). Potret Representasi Pedagogical Content Knowledge (PCK) Guru dalam Mengajarkan Materi Getaran dan Gelombang pada Siswa Smp. Indonesian Journal of Applied Physics, 5(01), 9. https://doi.org/10.13057/ijap.v5i01.252

Purwoko, R. Y. (2017). Urgensi Pedagogical Content Knowledge dalam Meningkatkan Kualitas Pembelajaran Matematika. Jurnal Pendidikan Surya Edukasi (JPSE), 3(2), 42-55.

Putnam, R. T., \& Borko, H. (2000). What Do New Views of Knowledge and Thinking Have to Say About Research on Teacher Learning? Educational Researcher, 29(1), 4-15. https://doi.org/10.3102/0013189X029001004

Sarkim, T. (2015). Pedagogical Content Knowlegde : Sebuah Konstruk untuk Memahami Kinerja Guru di Dalam Pembelajaran. Prosiding Pertemuan Ilmiah HFI Jateng Dan DIY XXIX, 53(25 April), 7-12.

Shulman, L. S. (1986). Those Who Understand: Knowledge Growth in Teaching. Educational Researcher, 15(2), 4-14.

Shulman, L. S. (1987). Knowledge and teaching: Foundations of the New Reform. Harvard Educational Review, 57(1), 1-21.

Solihin, R., Muin, M. T., \& Iqbal, M. (2021). Distance Learning: The Effectiveness Studies In College Students. Qalamuna - Jurnal Pendidikan, Sosial, Dan Agama, 13(1), 57-72. https://doi.org/10.37680/qalamuna.v13i1.709

Subhan, M. (2020). Analisis Penerapan Technological Pedagogical Content Knowledge (TPACK) Pada Proses Pembelajaran Kurikulum 2013 Di Kelas V SDN 018/VIII Muara Tebo. IJTVET, 1(2), 174-179.

Sulastri, R. (2016). KAJIAN PEDAGOGICAL CONTENTKNOWLEDGE CALON GURU. Jurnal Pendidikan Serambi Ilmu, 24(1), 67-70.

Turnuklu, E., \& Yesildere, S. (2007). The Pedagogical Content Knowledge in Mathematics: PreService Primary Mathematics Teachers' Perspectives in Turkey. Issues in the Undergraduate 
Mathematics Preparation of School Teachers, 1(October), 1-13.

Wentzel, K. R., \& Brophy, J. E. (2014). Motivating Students to Learn. In Business Communication Quarterly (Fourth Edi). Rotledge. https://doi.org/10.1177/108056990306600408

Yuliati, L. (2017). MEMBANGUN PEDAGOGICAL CONTENT KNOWLEDGE CALON GURU FISIKA MELALUI PRAKTEK PENGALAMAN LAPANGAN BERBASIS LESSON STUDY. Momentum: Physisc Education Journal, 1(1), 16-30. 